\title{
The Combination Effect of Simvastatin and Virgin Coconut Oil on Total Cholesterol Levels in Dislipidemic Male Albino Rats (Rattus norvegicus)
}

\author{
Lutfi Dewanda Nugroho' ${ }^{1}$, Soebagijo Adi Soelistijo ${ }^{2 *}$, Jusak Nugraha ${ }^{3}$
}

${ }^{1}$ Faculty of Medicine, Universitas Airlangga, Surabaya, Indonesia.

${ }^{2}$ Department of Internal Medicine, Faculty of Medicine, Universitas Airlangga, Surabaya, Indonesia.

${ }^{3}$ Department of Clinical Pathology, Universitas Airlangga, Surabaya, Indonesia.

A B S T R A C T

Introduction: Simvastatin is a primary pharmacological therapy for dyslipidemia (hypercholesterolemia). Virgin coconut oil (VCO) is a companion intake of statin drugs considered capable of lowering blood cholesterol levels. This study aimed to determine the combination effect of statin drug groups with VCO on total cholesterol.

Methods: The stages of this study started with the adaptation process of animals, giving a high-fat diet (HFD), and treatment with simvastatin and VCO. The adaptation process was conducted where the experimental animals were fed pellets and drank clean water in a container. A HFD was given by mixing pork brains with distilled water with a ratio of $1: 3$ as much as $2 \mathrm{ml}$ per day for 21 days. In simvastatin and VCO treatment for 7 days, the experimental animals were divided into 4 groups; group I was given aquades, group II was given VCO, group III was given simvastatin, and group IV was given simvastatin and VCO. The total cholesterol levels in the blood of albino rats were examined by employing a BS-300 Chemistry Analyzer through a spectrophotometric method. The total cholesterol levels data obtained were then examined for normality (Shapiro-Wilk test) and analyzed parametrically by utilizing One-way ANOVA.

Results: The average total cholesterol level in the negative control group (being given a standard diet) was $45.57 \mathrm{mg} / \mathrm{dL}$. The averages of blood total cholesterol levels were $47.28 \mathrm{mg} / \mathrm{dL}, 45.00 \mathrm{mg} / \mathrm{dL}, 46.85 \mathrm{mg} / \mathrm{dL}, 41.42 \mathrm{mg} / \mathrm{dL}$, and $44.28 \mathrm{mg} / \mathrm{dL}$ in the positive control group (given an HFD), in the treatment group I, in the treatment group II, in the treatment group III, and in the treatment group IV, respectively. There were no significant distinctions in the statistical test on decreasing blood total cholesterol among the negative control group, positive controls I, II, III, and IV.

Conclusion: Combination of simvastatin and VCO tends to reduce the total cholesterol level in albino rats. This is better than just giving VCO simvastatin alone.

\section{*Correspondence: soebagijo@yahoo.com}

JUXTA: Jurnal Ilmiah Mahasiswa Kedokteran Universitas Airlangga

p-ISSN: 1907-3623; e-ISSN: 2684-9453

DOI: 10.20473/juxta.V12I22021.66-71

Open access under Creative Commons Attribution-ShareAlike 4.0 International License $(\mathrm{CC}-\mathrm{BY}-\mathrm{SA})$
ARTICLE INFO

Article history:

Received 25 May 2021

Received in revised form 7 July 2021

Accepted 4 August 2021

Available online 31 August 2021

\section{Keywords:}

Disease,

Dyslipidemia,

Simvastatin,

Total cholesterol, VCO. 


\section{Introduction}

Dyslipidemia is a lipid metabolism disorder which is characterized by the up and down in lipid fractions that are contained in plasma. The main abnormality of lipid fractions is the increasing in total cholesterol, LDL cholesterol, TG, and decreased HDL cholesterol. ${ }^{1}$ Dyslipidemia is divided into two, primary dyslipidemia and secondary dyslipidemia. Primary dyslipidemia is a kind of dyslipidemia which is caused by genetic factor, while secondary dyslipidemia is a kind of dyslipidemia which is caused by lifestyle and other underlying diseases. Secondary dyslipidemia is divided into two: hypercholesterolemia and hypertriglyceridemia.

Hypercholesterolemia causes the formation of atherosclerotic plaques in blood vessels and the main causes of coronary heart disease and stroke. ${ }^{2}$

Coronary heart disease and stroke are the number one and two killers in the world. In 2014 coronary heart disease and stroke caused 14.1 million deaths in world. ${ }^{3}$ Furthermore, it increased in 2015 to 17.7 million people died of coronary heart disease, representing $31 \%$ of all deaths that emerge in the world. ${ }^{4}$ While the data in Indonesia in 2013, the prevalence of coronary heart disease in Indonesia was $0.5 \%$ or around 883,447 people. ${ }^{5}$

The American College of Cardiology (ACC) and American Heart Associatio (AHA) in 2013 recommend statin drugs as a primary pharmacological therapy for healing and reducing the risk of cardiovascular disease, caused by dyslipidemia. ${ }^{6}$ Departing from a study, it is shown that statin drug class in dyslipidemia is associated with a reduced risk of cardiovascular disease without looking at the absolute target of LDL cholesterol. ${ }^{7}$

Empirically, consuming VCO can help overcoming obesity, preventing coronary heart disease, atherosclerosis, and reducing cholesterol. ${ }^{8}$ In previous studies, VCO is able to reduce cholesterol levels and increase HDL levels, but not significantly different from statin drug administration as a means of lowering cholesterol in the blood. ${ }^{8}$ So far, there has been no scientific evidence as a solid basis for the potential combination of statin drug classes with VCO as a means of reducing blood cholesterol levels.

This study aims to determine the combination effect of statin drug groups with VCO on total cholesterol levels in dyslipidemic albino rats (Rattus norvegicus) which is one of the risk factors for cardiovascular disease.

\section{Methods}

\section{Material}

The study began after receiving a research ethics letter from the ethics committee of the Faculty of Veterinary Medicine, Universitas Airlangga.

This study employed 42 male wistar strain albino rats (Rattus novegicus) aged 2.5-3 months, weighing 150-250 grams which were obtained from the Laboratory of Department of Pharmacology of Faculty of Medicine,
Universitas Airlangga, Surabaya. Simvastatin, simvastatin suspension, and VCO were obtained from the Laboratory of Department of Pharmacology of Faculty of Medicine, Universitas Airlangga, Surabaya.

The dose of simvastatin in humans is $10 \mathrm{mg} /$ day. For the given dose to rats, we converted the dose of simvastatin based on the conversion table of Laurence and Bacharach (1984) which was $10 \mathrm{mg} /$ day $\times 0.018=0.18$ $\mathrm{mg} /$ day/200 g BB. Simvastatin suspension was obtained by dissolving simvastatin in CMC $1 \mathrm{~g}$ and $100 \mathrm{ml}$ distilled water. Therefore, the dose of simvastatin suspension that we gave to the rats for a day was $0.4 \mathrm{mg} / \mathrm{ml}(0.2 \mathrm{mg} / 0.5$ $\mathrm{ml}$ ). Whereas the VCO dose that was given to each albino rat followed the calculation of $0.81 \mathrm{~mL} /$ day/200 $\mathrm{g} \mathrm{BB}^{9}$. Because the utilized rat weight was $150-250$ grams, the dosage that might be given to rats in groups 3 and 4 was $0.81-1.01 \mathrm{ml} /$ day. To facilitate the process of giving VCO oil, the dose was $1 \mathrm{ml} /$ day.

To examine the total cholesterol levels, the rats were killed for the purpose of obtaining blood and put in plain blood tubes that had red cover. They were then centrifuged to get serum. The serum was then observed for total cholesterol levels by utilizing the BS-300 Chemistry Analyzer through adding special reagents to calculate total cholesterol levels. The results of calculating total cholesterol levels can be seen in a computer program that was connected to the BS-300 device.

Data on total cholesterol levels were performed descriptive and inferential analysis using Statistical Product and Service Solutions software. Inferential analysis included the normality test (Saphiro-Wilk test). If the data are not normally distributed, the relationships of each treatment group are analyzed non-parametically using the Kruskal Wallis Test. If the data is normally distributed then the relationship of each treatment group is analyzed parametrically with One-way ANOVA, and if the measurement results find a difference, followed by a post hoc test to determine the differences in each group.

\section{Experimental Procedure}

Albino rats were adapted in the cage for 1 week before being treated. Each cage comprised 7 rats so that each treatment group had 1 cage. In the control group, each group comprised 1 cage. During this adaptation period, rats were given a standard treatment viz. pellet feed and regular drinking of water.

After the 7th day, rats in the negative $\mathrm{COC}$ preliminary group were given a standard diet i.e. pellet feed and drinking water. Furthermore, 35 samples of remaining male albino rats on each group will be made dyslipidemia by means of feeding mixed HFD feed between the brains of pigs and distilled water. The feeding was conducted for 21 consecutive days, starting on the 8th day. After 21 days of $\mathrm{HFD}$ feeding, the $\mathrm{KOC}$ and $\mathrm{KO}$ control groups would have their blood total cholesterol levels being checked as confirmation that the rats had dyslipidemia. Rat blood in this group will be taken intracardially so that it would be able to kill the rats. 
On the 29th day they were treated based on their respective groups.

- Group 1 (7 rats) would be given a placebo in the form of an aquades for 7 days.

- Group 2 (7 rats) would be given VCO $0.81 \mathrm{~mL} /$ day/20 gram BB for 7 days.

- Group 3 (7 rats) would be given a simvastatin 0.5 $\mathrm{ml} /$ day for 7 days.

- Group 4 (7 rats) would be given simvastatin $0.5 \mathrm{ml} /$ day and VCO $0.81 \mathrm{~mL} /$ day/20 gram BB for 7 days.

In group 4, the distribution of simvastatin will be done 1 hour before VCO distribution. On the $35^{\text {th }}$ day, the blood would be collected to calculate the total blood cholesterol levels. Albino rats that had been sacrificed for their blood would die since their blood were taken through the intracardiac. The dead albino rats would be collected together and be buried since they were no longer employed.

\section{Results}

\section{Infection Evaluation}

The results of this experimental study obtained data in the form of independent variables viz. simvastatin, VCO, and the combination. While the dependent variable was total cholesterol levels in albino rat strains (Rattus novergicus). Total cholesterol levels in albino rats were examined by means of the BS-300 chemistry analyzer mindray which was available at Surabaya Regional Health Laboratory.

Based on the results of the calculation of the average total blood cholesterol levels that had been carried out obtained data as in Table 1.

Table 1. Results of examination of total cholesterol level $(\mathrm{mg} / \mathrm{dL})$ on 28 th day

\begin{tabular}{l|l|l|l|l|l|l}
\hline $\mathrm{N}$ & $\mathrm{K}-$ & $\mathrm{K}+$ & $\mathrm{P} 1$ & $\mathrm{P} 2$ & $\mathrm{P} 3$ & $\mathrm{P} 4$ \\
\hline 1 & 46 & 52 & 55 & 48 & 48 & 57 \\
2 & 42 & 46 & 48 & 47 & 46 & 49 \\
3 & 41 & 45 & 45 & 55 & 43 & 47 \\
4 & 46 & 47 & 45 & 48 & 46 & 51 \\
5 & 51 & 48 & 44 & 55 & 37 & 40 \\
6 & 47 & 54 & 41 & 41 & 36 & 38 \\
7 & 46 & 39 & 37 & 34 & 34 & 28 \\
\hline $\mathrm{X}$ & 45.57 & 47.28 & 45.00 & 46.85 & 41.42 & 44.28 \\
& \pm & \pm & $\frac{ \pm}{5.62}$ & $\frac{ \pm}{7.47}$ & $\frac{ \pm}{5.65}$ & $\frac{ \pm}{9.65}$ \\
\hline
\end{tabular}

\section{Information:}

$\mathrm{K}-\quad$ : Negative control group

$\mathrm{K}+\quad$ : positive control group

P1 : Treatment group 1, albino rats with placebo treatment in the form of aquades

P2 : Treatment group 2, albino with VCO treatment

P3 : Treatment group 3, albino rats with simvastatin treatment

P4 : Treatment group 4, albino rats were treated by means of simvastatin and VCO

$\mathrm{X} \quad$ : average total cholesterol $+\mathrm{SD}$
From the results of an average examination of total blood cholesterol levels (Table 1), in the negative control group, after 7 days of adaptation with standard feed, the average of blood total cholesterol levels was $45.57 \mathrm{mg} / \mathrm{dL}$. Standard feed content was $13 \%$ water content, $13-15 \%$ protein, $3 \%$ fat, $8 \%$ fiber, $6 \%$ ash, $0.8 \%$ calcium, $0.6 \%$ phosphorus. In the positive control group, the average of blood total cholesterol levels was $47.28 \mathrm{mg} / \mathrm{dL}$. In treatment group 1, the average of total blood cholesterol levels was $45.00 \mathrm{mg} / \mathrm{dL}$. In treatment group 2, the average of total blood cholesterol levels was $46.85 \mathrm{mg} / \mathrm{dL}$. In treatment group 3, the average of total blood cholesterol levels was $41.42 \mathrm{mg} / \mathrm{dL}$. In treatment group 4 , the average of blood total cholesterol level was $44.28 \mathrm{mg} / \mathrm{dL}$.

Departing from the results of the examination, the average of total cholesterol levels in the negative control group was compared to the positive control group which increased by $45.57 \mathrm{mg} / \mathrm{dL}$ and $47.28 \mathrm{mg} / \mathrm{dL}$. While between the positive control group compared to the treatment group 1 there was a decrease of $47.28 \mathrm{mg} / \mathrm{dL}$ and $45.00 \mathrm{mg} / \mathrm{dL}$. While between treatment group 1 compared to treatment group 2 there was an increase of $45.00 \mathrm{mg} / \mathrm{dL}$ and 46.85 $\mathrm{mg} / \mathrm{dL}$. While between treatment groups 2 , compared to treatment group 3, there was a decrease of $46.68 \mathrm{mg} / \mathrm{dL}$ and $41.42 \mathrm{mg} / \mathrm{dL}$. Whereas between treatment group 3 , compared to treatment group 4 , there was an increase of $41.42 \mathrm{mg} / \mathrm{dL}$ and $44.28 \mathrm{mg} / \mathrm{dL}$. Based on the results of the research that had been conducted, the obtained data were as shown in Figure 1.

Figure 1. Graph of average total cholesterol levels for each group

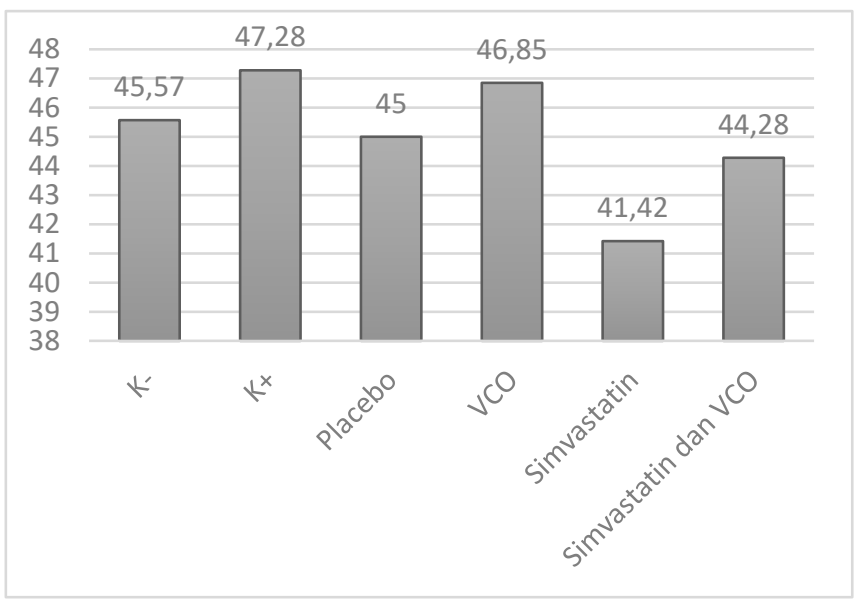

Data analysis process within this study started with normality test by applying Shapiro-Wilk test. In this study, group $\mathrm{K}-, \mathrm{K}+, \mathrm{K} 1, \mathrm{~K} 2, \mathrm{~K} 3$, and $\mathrm{K} 4$ showed that $p>0.05$ which indicated that total cholesterol level data were normally distributed. As the data were normally distributed, then the next test was Test of Homogeneity of Variances.

On the Test of Variance Homogeneity with levene showed that $p=0,136$ which indicated that variance of the six groups was homogenous $(p>0.05)$. Since the data variance was the same or homogenous, then our further test was One Way Anova. 
On one-way Anova test, it revealed that $p=0.588$ which indicated that $\mathrm{H}_{0}$ was failed to be rejected $(\mathrm{p}>0.05)$. This revealed that there was no significant distinction (meaningless) on the reduction of total blood cholesterol among group $\mathrm{K}-\mathrm{K}+, \mathrm{K} 1, \mathrm{~K} 2$, $\mathrm{K} 3$, or $\mathrm{K} 4$. Thus, post hoc test was not needed.

\section{Discussion}

This study utilized 42 types of experimental animals male wistar strain rats (Rattus norvegicus) were healthy, weighing 150-250 grams, and aged 2.5-3 months. The purpose of this study was to compare the total cholesterol levels in the blood of albino rats after distribution of simvastatin, VCO, or a combination of both. The stages of this study began with the adaptation process of animals to adjust to the environment in the cage, giving HFD with the aim that the experimental animals experience dyslipidemia (hypercholesterolemia or hypertriglyceride), and treatment by simvastin and VCO. In the adaptation process that was carried out in a standard way, the experimental animals were fed pellets and drank clean water in a container. They were given HFD by mixing pork brains with distilled water with a ratio of $1: 3$ as much as $2 \mathrm{ml}$ per day for 21 days. In simvastatin and VCO treatment for 7 days, the experimental animals were divided into 4 groups, group I was given aquades, group II was given VCO, group III was given simvastatin, group IV was given simvastatin and VCO. In this study the observed parameters were total cholesterol levels in the blood of albino rats that were examined by means of a BS-300 Chemistry Analyzer through the spectropometric method.

Based on laboratory data, the total cholesterol content of rats in the negative control group was $45.57+3.30$ $\mathrm{mg} / \mathrm{dL}$. This was in accordance with the previous literature study which stated that the normal level of total cholesterol in albino rats was $32+13.13 \mathrm{mg} / \mathrm{dL}^{9}{ }^{9}$ While the total cholesterol level of albino rats that were given HFD for 21 days in the positive control group was $47.28+4.88 \mathrm{mg} / \mathrm{dL}$, with a one-way Anova follow-up test showed no significant difference, compared to albino rats that were given a standard diet in negative control group. It emerged since albino rats did not have bile or bile duct (ductal choledocus) as it is described in Jose Behar's (2016) literature study on the physiology and pathophysiology of the biliary tract, gallbladder and sphincter oddi. ${ }^{10}$ The absence of bile or bile ducts in rats is also conveyed by Vdoviakova K (2016) in her literature study which discussed the importance of morphology and vasculis of rat heart in surgical research. ${ }^{11}$ Because of the absence of bile, rats get difficulty and take longer to digest and absorb fat. This is also explained in Jose Behar's notion (2016) which states that in the duodenum and jejunum, bile salts play a role in digestion and absorption of fat, one of which is cholesterol. ${ }^{10}$ In the article Daniel TF (2009) it was explained in more detail that early fat digestion, from the oral cavity to the intestinal duodenal sub-layer, produces a rough emulsion that comprises free cholesterol, triglycerides, free fatty acids, and phospholipids. When these emulsions are sent to the intestine, they are mixed with micelles of bile salts, which are synthesized and secreted into the intestine from the liver through the bile duct. The total concentration of micelles of bile salts is positively correlated to cholesterol absorption. Since bile salts micelle emulsion lipid is catalysis to smaller drop, it can make the interaction easier with lipase enzyme for hydrolysis by lipase pancreas and carboxyl ester lipase (CEL) that gives impact in normal cholesterol absorption, and the making of chylomicron. ${ }^{12}$ It shows that giving HFD to the laboratory rat needs more time to obtain the increasing of total cholesterol in blood. Besides that, based on Maurice (2006) explanation, cholesterol, which is consumed (exogenous), only has effects around $40 \%$ to $65 \%$ in increasing blood total cholesterol levels. ${ }^{13}$ This is caused by consuming cholesterol (exogenous) will decrease production of cholesterol (endogenous).

Since there is no significant difference between positive control group and negative control group,in this case, the researcher cannot make trial animal model dyslipidaemia in estimated time. Therefore, it is needed a further analysis about the effect of time of giving HFD toward the increasing total cholesterol levels to laboratory rat until it gets dyslipidaemia.Regarding to that, it is required a deep research about the effect of administration HFD duration toward increasing cholesterol level of albino rat until reaching dyslipidaemia.

The researcher is continued by administration medical treatment to albino rats, which are divided into four groups. The first group receives seven days treatment of additional HFD and administration placebo, Distilled water, the second group receives HFD and VCO in seven days, the third group receives HFD and simvastatin in seven days, and the fourth group receives HFD and mixed therapy of VCO and simvastatin in seven days. The dose of simvastatin for human is $10 \mathrm{mg} /$ day. For the dose that is given to the rat, we convert based on Laurence and Bacharach table conversion (1984), which is $10 \mathrm{mg} /$ day $x$ $0.018=0.18 \mathrm{mg} / \mathrm{day} / 200 \mathrm{~g}$ BB. The suspension of simvastatin is obtained by melting simvastatin into CMC 1 $\mathrm{g}$ and Distilled water $100 \mathrm{ml}$. Therefore, the dose of simvastatin suspension that we give to the rat is $0.4 \mathrm{mg} / \mathrm{ml}$ $(0.2 \mathrm{mg} / 0.5 \mathrm{ml})$ in a day for each rat. While dose of VCO that is given to each albino rat follows the calculation 0.81 $\mathrm{ml} /$ day $/ 200 \mathrm{~g} \mathrm{BB} .{ }^{14}$ Because the weight of rat that is used is 150 to 250 grams, it makes the allowed dose for rat group three and four is $0.81-1.01 \mathrm{ml} /$ day. To make the VCO administration process, each rat is given $1 \mathrm{ml}$ in a day. VCO and simvastatin is to the fourth group is given by an hour interlude to prevent the interaction of medicine and supplement. After seven days of medical treatment, 28 rats were sacrificed to obtain the blood and transfer it into the blood tube plain which has red cover, then is decentrifugation for gaining the serum. Then, the cholesterol level of the serum is observed by using BS-300 Chemistry Analyzer aid through additional special reagent for counting the total of the cholesterol level. The result of 
cholesterol level calculation can be known in computer software, which is connected to the BS-300.

The average of total cholesterol level for each group is as follows, first group has $45.00 \mathrm{mg} / \mathrm{dL}$ average. Second group has $46.85 \mathrm{mg} / \mathrm{dL}$ average. Third group has 41.42 $\mathrm{mg} / \mathrm{dL}$ average. Fourth group has $44.28 \mathrm{mg} / \mathrm{dL}$. The chart on 5.1 picture can make easier observation toward the average of total cholesterol level for each group. The group, which is given VCO, tend to has higher result of average total cholesterol than the group, which is only given placebo in the form of distilled water. Besides, the group which was given mixed treatment simvastatin and VCO tend to have higher result of average total cholesterol than the group, which is only given simvastatin. In this research, the result shows that administration VCO tent to increase blood total cholesterol level compared by administration simvastatin or placebo Distilled water. The result accorded with the research, which is done by Yudha and Tesminatum (2008), that says if we give $5 \%$ to the VCO, which contains medium chain trygliserida (MCT/C6-C2/) and natural saturated fat, can increase the total cholesterol level. ${ }^{15}$ In other research, conducted by Voon PT, et al. (2011) in Chinwong S, et al. (2017) says that the increasing of total cholesterol level and LDL significantly to the sample, which $2 / 3$ of diet total is changed by coconut oil. ${ }^{16}$ Similar result is also found in Fisher EA's research (1983), which says about the independent effect of saturated fat diet and cholesterol to plasma lipid, lipoprotein, and apolipoprotein E. In his research, coconut oil diet relates to the increasing of total cholesterol and others eight variable. ${ }^{17}$

In Reiser R's research (1985) also mentions that total cholesterol levels in cow fat adduction is lower than coconut oil adduction. ${ }^{18}$ This is also in line with research which is done by Ng TK (1991), it says coconut oil can increase total cholesterol concentration in serum, different from coconut oil administration or corn oil, which can decrease significantly total cholesterol levels. ${ }^{19}$ Based on researches above, it can be concluded that the increasing of total cholesterol levels in participants, which consume VCO, is caused by saturated fatty acids in VCO. The result is like the Mensink RP research (1992), who is done metanalysis from 27 experiment on lipid level and lipoprotein. The research evaluates three effect of fatty acids, which are saturated fatty acids, unsaturated fatty acids, and polyunsaturated fatty acids.Among those three fatty acids, unsaturated fatty acids have the biggest increasing in total of cholesterol lipid level, HDL, and LDL. On the other hand, saturated fatty acids and polyunsaturated fatty acids have decreasing in total of cholesterol levels and LDL. ${ }^{20}$ This current result makes hypothesis, which was made by the researcher, is denied. Possibly this result is happened because its cardioprotective effect through antisterosclerotic has bigger impact rather than its antihypercholesterolemia. According to Nevin KG (2004) and (2009), in his research he stated that VCO biologically contains active polyphenol and it shows radical activity in preventing and decreasing oxidation of LDL in vitro. ${ }^{21,22}$ Also, the previous literature review stated VCO contains flavonoid, which can hold up the LDL oxidation and increase the NO production, moreover, VCO contains tocopherol and tocotrienol that make LDL oxidation become slow and platelet aggregation. And antihypercholesterolemia, which is caused by tocopherol and tocotrienol, can slow down the reduction of HMG CoA and flavonoid reduces the speed of forming apoB and TG

The increasing of the average total cholesterol level on mice, which get VCO treatment, is not in accordance with the researcher hypothesis, this possibly came from low quality VCO that is used in the research. Based on the research, which was done by Yudha and Tesminatum (2008), states that VCO can be defective in processing, heating, and saving progress. On the saving process, VCO can be defective if the quality of its oil is changed, it is happened because the hydrolysis fatty acids have potential to increase cholesterol levels. The fatty acids can be hydrolysed because of water and lipase enzyme that is obtained from living moulds or filamentous fungi in VCO. VCO also can be defective because of high temperature, which makes fatty acids of VCO turns into trans fatty acids (TCA), this is can increase the cholesterol levels. ${ }^{15}$

Although the average total of cholesterol level which has given VCO was slightly higher than the group who has been given by placebo in the form of aquades and the average total of cholesterol level in the group treated with the combination of simvastatin and VCO was slightly higher than the group who has given simvastatin only, but the data average total of cholesterol level of the four groups after we conduct follow-up test one-way annova, it shows no significant differences between groups 1,2, 3, and 4. This was due to the researchers' failure to make animal models, then try the positive and negative control groups that are incorporated in the preliminary test in the time frame that was previously planned. This preliminary test was carried out because it was not possible to conduct a pre-post experiment since it was not possible to conduct a pre-post experiment as the blood of rats which had to be taken intracardially was $3 \mathrm{ml}$. Therefore, to compare the total decreases of cholesterol levels, a preliminary test group or a positive control group was formed which first thing needs to be found is its mean.

Since the researcher was not able to make the experimental animal model, so we do not need to compare the treatment groups $1,2,3$, and 4 with the preliminary test group. We only compare the average data of total cholesterol levels in the blood of albino rats without dyslipidemia in groups 1, 2, 3, and 4. From the previous explanation, we can get the information that the group of albino rats who has given VCO, the average of total cholesterol level tends to be higher if we compare it with the group of albino rats that we only give placebo in the form of aquades. In other hand, the group of albino rats that we treated simvastatin, the average total of cholesterol levels tended to be lower when compared to the group of albino rats that we gave placebo and VCO treatments. Moreover, the group of albino rats that we treated with a combination of simvastatin and VCO, their average of total 
cholesterol level tended to be higher when compared to the group of albino rats that we gave simvastatin, and tended to be lower if we compared the group of albino rats that we gave placebo treatment and VCO only.

\section{Conclusion}

The combination of simvastatin and VCO tends to reduce total cholesterol levels in albino rats. This is better than just giving VCO or simvastatin alone. However, this result can change if we give treatment to albino rats that have dyslipidemia. Therefore, the further research is needed on the effectiveness of the combination of simvastatin and VCO in dyslipidemic albino rats.

\section{Acknowledgments}

1. Jefferson Caesario, Faculty of Medicine, Universitas Airlangga, as a research assistant.

2. Laboratory workers in the Pharmacology Laboratory, Department of Pharmacology and Therapy; Microbiology Laboratory, Department of Microbiology; Histology Laboratory, Department of Anatomy and Histology; Anatomy Pathology Laboratory, Department of Anatomy Pathology, Faculty of Medicine, Universitas Airlangga.

\section{CONFLICT OF INTEREST}

The author stated there is no conflict of interest in this study.

\section{REFERENCES}

1. (PERKENI) PEI. Panduan Pengelolaan Dislipidemia di Indonesia 2015. Jakarta: Perkumpulan Endokrinologi Indonesia (PERKENI), 2015.

2. Hardman JG, Limbird LE. Goodman \& Gilman: Dasar Farmakologi Terapi. 10th ed. Jakarta: EGC, 2007.

3. Organization WH. World Health Statistics 2014: A Wealth of Information on Global Public Health. Geneva, 2014.

4. Organization WH. Cardiovascular Diseases (CVDs). Geneva, 2017.

5. Indonesia KKR. Riset Kesehatan Dasar 2013. Jakarta, 2013.

6. Stone NJ, Robinson JG, Lichtenstein AH, et al. 2013 ACC/AHA Guideline on the Treatment of Blood Cholesterol to Reduce Atherosclerotic Cardiovascular Risk in Adults: A Report of the American College of Cardiology/American Heart Association Task Force on Practice Guidelines. J Am Coll Cardiol 2014; 63: 2889-2934.

7. Jacobson TA, Ito MK, Maki KC, et al. National Lipid Association Recommendations for Patient-
Centered Management of Dyslipidemia: Part 1 Executive Summary. J Clin Lipidol 2014; 8: 473488.

8. Harini M, Astirin OP. Blood Cholesterol Levels of Hypercholesterolemic Rat (Rattus norvegicus) after VCO Treatment. Nusant Biosci 2009; 1: 5358.

9. Smith JB, Mangkoewidjojo S. Pemeliharaan, Pembiakan dan Penggunaan Hewan Percobaan di Daerah Tropis. Jakarta: UI Press, 1988.

10. Behar J. Physiology and Pathophysiology of the Biliary Tract: The Gallbladder and Sphincter of Oddi-A Review. ISRN Physiol; 2013. Epub ahead of print 24 February 2013. DOI: 10.1155/2013/837630.

11. Vdoviaková K, Vdoviaková $\mathrm{K}$, Petrovová $\mathrm{E}$, et al. Importance Rat Liver Morphology and Vasculature in Surgical Research. Med Sci Monit 2016; 22: 4716-4728.

12. Daniels TF, Killinger KM, Michal JJ, et al. Lipoproteins, Cholesterol Homeostasis and Cardiac Health. Int $J$ Biol Sci 2009; 5: 474-488.

13. Ross AC, Caballero B, Cousins RJ, et al. Modern Nutrition in Health and Disease. 11th ed. Philadelphia: Wolters Kluwer Health/Lippincott Williams \& Wilkins, 2014.

14. Dayrit CS. Coconut Oil: Atherogenic or Not? (What therefore causes Atherosclerosis?). Philipp J Cardiol; 31.

15. Yudha RP, Tasminatun S. Pengaruh Virgin Coconut Oil terhadap Kadar Kolesterol, HDL dan LDL Tikus Putih (Rattus norvegicus). Mutiara Med J Kedokt dan Kesehat 2008; 20-26.

16. Chinwong S, Chinwong D, Mangklabruks A. Daily Consumption of Virgin Coconut Oil Increases HighDensity Lipoprotein Cholesterol Levels in Healthy Volunteers: A Randomized Crossover Trial. Evid Based Complement Alternat Med 2017; 2017: 7251562.

17. Fisher EA, Blum CB, Zannis VI, et al. Independent Effects of Dietary Saturated Fat and Cholesterol on Plasma Lipids, Lipoproteins, and Apolipoprotein E. $J$ Lipid Res 1983; 24: 1039-1048.

18. Reiser R, Probstfield JL, Silvers A, et al. Plasma Lipid and Lipoprotein Response of Humans to Beef Fat, Coconut Oil and Safflower Oil. Am J Clin Nutr 1985; 42: 190-197.

19. $\mathrm{Ng} \mathrm{T,} \mathrm{Hassan} \mathrm{K,} \mathrm{Lim} \mathrm{J,} \mathrm{et} \mathrm{al.} \mathrm{Nonhypercholesterolemic}$ Effects of a Palm-Oil in Malaysian Volunteers. Am J Clin Nutr 1991; 53: 1015S-1020S.

20. Mensink RP, Katan MB. Effect of Dietary Fatty Acids on Serum Lipids and Lipoproteins. A Meta-Analysis of 27 Trials. Arterioscler Thromb A J Vasc Biol 1992; 12: 911-919.

21. Nevin KG, Rajamohan T. Beneficial Effects of Virgin Coconut Oil on Lipid Parameters and In Vitro LDL Oxidation. Clin Biochem 2004; 37: 830-835.

22. Nevin KG, Rajamohan T. Wet and Dry Extraction of Coconut Oil: Impact on Lipid Metabolic and Antioxidant Status in Cholesterol Coadministered Rats. Can J Physiol Pharmacol 2009; 87: 610-616. 